BULLETIN Bulletin hispanique

HISPANIQUE Université Michel de Montaigne Bordeaux

114-2 | 2012

Varia

\title{
El motivo de la muerte en los libros de caballerías
}

articulación narrativa y sentido histórico

\section{Luis Galván}

\section{CpenEdition}

Journals

Edición electrónica

URL: https://journals.openedition.org/bulletinhispanique/1368

DOI: 10.4000/bulletinhispanique.1368

ISSN: 1775-3821

Editor

Presses universitaires de Bordeaux

Edición impresa

Fecha de publicación: 31 diciembre 2012

Paginación: 519-539

ISBN: 978-2-86781-855-4

ISSN: 0007-4640

Referencia electrónica

Luis Galván, «El motivo de la muerte en los libros de caballerías», Bulletin hispanique [En línea], 114-2 |

2012, Publicado el 05 enero 2016, consultado el 30 julio 2022. URL: http://journals.openedition.org/

bulletinhispanique/1368 ; DOI: https://doi.org/10.4000/bulletinhispanique.1368

All rights reserved 


\title{
El motivo de la muerte en los libros de caballerías: articulación narrativa y sentido histórico
}

\author{
Luis GaLván \\ Universidad de Navarra-GRISO - España
}

Le motif de la mort, principe de répétition et de transformation, régit la dynamique narrative des livres de chevalerie espagnols et leur donne forme et sens, en reliant temps individuel et temps collectif. De plus, le chronotope du corps qui vit et meurt rapproche le monde de la fiction du monde réel du lecteur.

Mots-clés : mort, narratologie, chronotope, romans chevaleresques.

El motivo de la muerte es un principio de repetición y transformación que gobierna el dinamismo de la trama de los libros de caballerías castellanos y les da forma y sentido, sirviendo de mediación entre el tiempo individual y el colectivo. Además, el cronotopo del cuerpo humano que vive y muere media entre el mundo de la ficción y el mundo real de los lectores.

Palabras claves: muerte, narratología, cronotopo, libros de caballerías.

The motive of Death, principle for repetition and transformation in Castilian chivalric romance, governs the dynamics of plot and provides the stories form and meaning by linking both individual and collective times. Furthermore, the chronotope of the living and dying human body also makes a link between the world of fiction and the real world of the reader.

Keywords: death, narrative theory, chronotope, chivalric romances.

E L éxito de los libros de caballerías suele provocar una sorpresa algo escandalizada: «Pero, ¿por qué los caballeros españoles del siglo XVI, que no todos eran intelectualmente mediocres, tanto apreciaron y por tanto tiempo una literatura que en muchos casos nos parece de mala calidad, y casi siempre indigesta?» (Chevalier 96). La respuesta se ha buscado mayoritariamente, 
durante las últimas décadas, por el camino del historicismo y la ideología ${ }^{1}$. Siendo innegable el interés de algunos resultados obtenidos con este enfoque, no está de más señalar su parcialidad, al olvidarse de que el público de entonces no era totalmente distinto del actual. Quizá parece ingenuo Menéndez Pelayo cuando escribe que aquellos libros satisfacían «necesidades eternas de la mente humana» (461-62); pero no lo es tanto al señalar que hablan "de armas y de amores, materia siempre grata a mancebos enamorados y a gentiles damas» (463), pues esto podría traducirse algo cínicamente: hablan de erotismo y violencia, recursos inagotables del entretenimiento de masas en todas las épocas.

El presente trabajo pretende explorar una vía intermedia, una cuestión en que las mujeres y hombres del XVI eran en parte iguales y en parte diferentes de nosotros. Como nosotros, iban todos a morir y lo sabían; a diferencia de nosotros, contaban con un incesante, omnipresente discurso sobre la muerte. La indagación de este discurso permitirá delinear mejor el horizonte de lectura, para percibir un doble relieve: el de los elementos relativos a la muerte en la dinámica textual de los libros de caballerías, y el de estos libros en la experiencia verbal e imaginativa del público.

Los estudios de Literatura suelen abordar la muerte desde un punto de vista semántico general, como representación de costumbres y mentalidades, o como tema ficcional ${ }^{2}$; en cambio, no está tan desarrollado su análisis como un motivo que se articula con otros para configurar el mundo del texto y provocar un dinamismo de narración y lectura, y para constituir un sentido que se pueda proyectar en la experiencia. Por eso, comenzaré por exponer algunas aproximaciones a estos aspectos, de las que se desprende una heurística que aplicaré a lo largo del trabajo.

En primer lugar, hay que considerar la muerte en cuanto motor del dinamismo de la narración y clave de su sentido, como explican Walter Benjamin y Peter Brooks. Cuando comienza un relato, el lector se interesa por unos personajes, y surge la perspectiva de llegar a un final que bien puede ser la muerte de ellos; así pues, la cuestión clave es: "¿cómo le dan a conocer que la muerte ya los está esperando, una muy concreta, y en un lugar muy concreto?» (Benjamin 456; traducción mía). Ese cómo es el propio trabajo del texto, el hiato entre comienzo y fin, origen y muerte, abierto por la dilación y la diferencia mediante una serie de transformaciones. El comienzo se va trasformando en final a través de varias fases, cada una de las cuales conserva algo igual y aporta algo diferente. Este juego de repetición y novedad produce una forma perceptible y reconocible, y una orientación hacia un final y una muerte que se reconozcan

1. Ver Chevalier 96-103; Eisenberg 41-44; y, entre los trabajos recientes, Cuesta Torre, 2002; Lucía Megías; Rodríguez Velasco.

2. Como en los trabajos de historia de Tenenti, Ariès, y Vovelle, así como en el estudio propiamente literario de Picard. Naturalmente, también abundan los estudios de detalle sobre la muerte en obras particulares; por ejemplo, ver el libro de Casta, y los volúmenes dirigidos por Garreau; Jacquin; y Zanatta. 
como apropiados (Brooks, 1984, 100-03). Es lo que Derrida llama la «pulsión» o «ley de lo propio» $(378-82)^{3}$.

En segundo lugar, la muerte es constitutiva de la intrínseca conexión de tiempo y espacio literarios que Bakhtin denomina "cronotopo». Bakhtin considera que el papel de la muerte distingue particularmente el cronotopo folklórico del histórico o ideológico. El primero presenta la vida común del grupo humano, que continúa y crece más allá de las muertes individuales, absorbidas en el proceso vital, mientras que el segundo se limita al individuo aislado y por tanto presenta la muerte como fin último, esencialmente opuesto a la vida (206-16). El funcionamiento literario del cronotopo folklórico se muestra en la interpretación de la obra de Rabelais. Esta se construye a partir de una ecuación fundamental entre el valor de las cosas y su extensión espaciotemporal -ecuación que Bakhtin interpreta como estimación del mundo físico propia del Renacimiento, en contraste con la Edad Media (167-68)-. Siendo la vida el valor supremo, Rabelais la presenta como algo infinito, mediante una inmortalidad biológica e histórica: la prolongación del linaje en las sucesivas generaciones y la continuidad y el progreso de los logros culturales, que la muerte individual no puede interrumpir (Bakhtin 201-04). La muerte queda entonces naturalizada, asociándose a la fisiología y a la risa (193-200). Lo que Bakhtin deja en la sombra, con su polarización -sobre la matriz naturaleza/ historia- entre colectividad folklórica e individualismo ideológico, es el aspecto natural de la muerte del individuo ${ }^{4}$; un aspecto que puede recuperarse considerando su papel en la relación de autor y lector.

En tercer lugar, pues, hay que poner la muerte en el marco de la comunicación literaria. Precisamente, la mortalidad es un lazo que une el cronotopo representado en la obra y el cronotopo de la comunicación entre autor y lector, cronotopos que, como señalan Bakhtin, son esencialmente distintos, irreductibles (254-57). «Every work has a beginning and an end, the event represented in it likewise has a beginning and an end, but these beginnings and ends lie in different worlds» (255; cursiva original). Ahora bien, si el final de lo narrado es una muerte en el mundo ficticio, entonces se trata del mismo final que tendrán el autor y el lector en el mundo real: esto fundamenta la autoridad del narrador y enciende la curiosidad del lector; los acerca, los hace formar una comunidad donde se comparten experiencias con sentido (Benjamin 449-50, 456-57; Brooks, 1993, 83-84). Al tomar en consideración la mortalidad de los personajes, llegamos a la presencia de personas, autores y lectores con una determinada conciencia de sí, de sus cuerpos. Cuerpos que son cronotopos indi-

3. Tanto Brooks como Derrida comentan ese extrańo texto que es Jenseits des Lustprinzips de Freud.

4. También deja en la sombra el valor de la vida individual, lo que tiene connotaciones totalitarias, algo aliviadas por la prestidigitación que equipara el morir humano con el plantar la semilla: «Perishing and death are perceived as a sowing, after which follows increase and harvest, multiplying that which has been sown" (207; cursiva original). El juego recuerda el dicho de Marx: «la violencia es la partera de la historia», donde el matar se convierte en dar a luz (ver Arendt 287-98). 
viduales y naturales: realidades físicas sometidas a transformación en el tiempo -crecimiento, maduración, envejecimiento- hasta que mueren y desaparecen del espacio, ya no están.

En resumen, se propone aquí un estudio del papel de la muerte en la estructura narrativa y comunicativa de los libros de caballerías, previa reconstrucción del horizonte configurado por el discurso normativo de su época. Por las coordenadas históricas y culturales de estos libros, su estudio puede servir de complemento y contraste para las perspectivas teóricas que se han esbozado. ¿Cuál es el juego de dilaciones y repeticiones, cuál es la «ley de lo propio» en unos libros que permiten -a diferencia de las novelas modernas que examina Brooks- posponer el final de entrega en entrega, o suspender las leyes de la naturaleza? Si el tratamiento de la muerte diferencia los cronotopos de la Edad Media y el Renacimiento, del folklore y la ideología tal como plantea Bakhtin, ¿qué forma tiene en unos libros que son híbridos de todas esas categorías? Si la transformación de la muerte en la época contemporánea, su confinamiento y expulsión de la vida cotidiana entorpece la comunicabilidad de la experiencia, como dice Benjamin (449), ¿qué posibilidades de comunicación había en tiempos anteriores, en la época de la muerte conspicua y reglada? En fin, este trabajo pretende contribuir a elaborar una alteridad que pueda servir, como contraste, para la comprensión de la experiencia y los tabúes de la muerte en la sociedad contemporánea (Elias; Eagleton 215-28).

\section{LA MUERTE Y LOS LECTORES}

Hay que comenzar considerando en qué medida era la muerte de los personajes de ficción un elemento significativo para los lectores del siglo XVI. A la evidente dificultad de acceder a la experiencia de los antiguos lectores, para los libros de caballerías se añade el sesgo polémico de muchos testimonios 5 . Por ejemplo, cuando López Pinciano relata que un lector, ante la muerte de Amadís de Gaula, lloró hasta perder el conocimiento, lo hace para reprobar su actitud y la afición a los libros de caballerías en general (ii: 170-74). Sea verdad o no la anécdota -López Pinciano debió de considerarla, al menos, verosímil ${ }^{6}-$, resulta a la vez llamativa y trivial, porque apenas informa sobre el contenido ni el horizonte de la lectura. Para esto, hay que analizar algunas observaciones más heterogéneas.

Fray Luis de Granada, que también deplora la afición de la gente a tales libros, se pregunta: ¿qué los mueve a leerlos? Y responde:

entre todas las obras humanas que se pueden ver con ojos corporales, las más admirables son el esfuerzo y fortaleza. Porque, como la muerte sea, según Aristóteles dice, la última

5. Glaser ofrece bastante material sobre esta polémica; para su contexto ideológico, ver Bataillon 614-29; Galván, 2009c.

6. Relata un caso parecido Francisco de Portugal en Arte de galantería (citado en Thomas 62). 
de las cosas terribles y la cosa más aborrecida de todos los animales, ver un hombre despreciador y vencedor de este temor tan natural causa grande admiración en los que esto ven. [...] Pues esta admiración es tan común a todos y tan grande, que viene a tener lugar no sólo en las cosas verdaderas, sino también en las fabulosas y mentirosas. Y de aquí nace el gusto que muchos tienen de leer estos libros de caballerías fingidas. (Introducción, II, xvii: 156-57) ${ }^{7}$

Se ve aquí, en primer lugar, que la muerte es un horizonte para las acciones del caballero: no sería admirable si no corriese peligro de morir. Ahora bien, el mismo horizonte tienen los lectores en su propia vida, o cuando menos algunos de ellos; y así, otro autor eclesiástico, fray Jaime de Alcalá, justifica la afición a estos libros en «los caballeros y personas que con la lanza en la mano son obligados y su linaje y virtud los convida y fuerza para morir por la justicia» (8). En segundo lugar, la referencia a Aristóteles puede resultar un tópico más o menos natural en este contexto, pero no deja de ser un eco de las artes de bien morir, que solían comenzar precisamente así: «maguer segund el Philósofo en el tercero de las Ethicas, la más espantable de las cosas terribles sea la muerte» $(\text { Arte-a } 81)^{8}$; «de todas las cosas espantosas, la más espantosa es la muerte. Esto dixo un philósopho bien afamado» (Erasmo, Preparación, 217) ${ }^{9}$. Bastantes lectores desconocerían a Aristóteles y estarían en cambio familiarizados con estas artes, que son uno de los principales discursos normativos sobre la muerte en los siglos XV y XVI, sobre el cual habrá que volver.

Otro testimonio que apunta en la misma dirección es el elogio de Tirante el Blanco que se pronuncia en el Quijote ${ }^{10}$ : «por su estilo es este el mejor libro del mundo: aquí comen los caballeros, y duermen y mueren en sus camas, y hacen testamento antes de su muerte, con estas cosas de que todos los demás libros deste género carecen» (I, vi: 77). Hay, pues, una imagen de la muerte que se considera normal y que se echa de menos en los libros de caballerías. Y los dos elementos mencionados vuelven a remitir a las artes de bien morir. El centro de su iconografía es precisamente el lecho de muerte, donde ángeles y demonios se disputan el alma del moribundo (Gago 52-73; Ariès 110-17; Vovelle 14346); y el testamento es una de las medidas que intiman para alcanzar la paz y la salvación (Ariès 187-92; Vovelle 168-74).

En resumen, se puede concluir que la muerte es un foco de interés para los lectores de caballerías; que su representación en estos libros contrasta con otras que se consideran más normales o edificantes; y que un punto de referencia para esta norma lo constituyen las artes de bien morir. Procede ahora, por tanto, considerar el papel de estas y de otros discursos análogos en la en la

7. Para facilitar la localización de las citas y referencias a las fuentes, se indica: en números romanos mayúsculos, el libro o parte (si hay); en romanos minúsculos, el capítulo (si hay); en arábigos, la página de la edición utilizada.

8. Ver también Arte-b, a.ii.

9. Cito la traducción castellana de Pérez de Chinchón, que tuvo cinco ediciones en el siglo XVI; para el texto latino, ver Erasmo, «De praeparatione», 339.

10. Posiblemente el pasaje es irónico como tal elogio, sobre todo en el contexto de otras alusiones pormenorizadas; ver Eisenberg 147-58, y Lawrance, 1999, 97. 
configuración de un horizonte social acerca de la muerte, sobre el cual se recortará la imagen que ofrecen los libros de caballerías.

\section{EL DISCURSO NORMATIVO}

Es cosa conocida que las actitudes ante la muerte en Europa Occidental sufren un cambio significativo a mediados del siglo XIV, y que en el siglo XV aparece un discurso que adquiere gran difusión manuscrita e impresa, en latín y en lenguas vernáculas, durante muchas décadas: las mencionadas Artes moriendi o Artes de bien morir ${ }^{11}$. Estos libros se ocupan principalmente de la experiencia espiritual del moribundo: las tentaciones que sufrirá y sus remedios. La versión más breve y popular contiene poco más que esto, junto con ilustraciones xilografiadas; la versión larga ańade instrucciones sobre los últimos sacramentos, el testamento y las oraciones apropiadas. A vueltas con estas recomendaciones prácticas se va dando una visión de la vida y de su sentido y valor en el umbral, si no en las fauces, de la muerte. Se recomienda que se medite con frecuencia en ella (Arte-a 82), y se hace notar su omnipresencia en una variedad de formas:

a los que han de morir, muy grand dolor corporal acaesce, mayormente a aquellos que mueren non por muerte natural, la qual viene muy pocas vezes, assí como lo enseña la experiencia; mas antes viene, por la mayor parte, por acidentes, assí como de fiebre, apostema o otra enfermedad aflitiva e atormentante. (Arte-a, v: 99-100)

Las consideraciones en este sentido son más amplias en otras obras análogas. Por ejemplo, el Arte de bien morir de Rodrigo de Santaella ${ }^{12}$, presenta las «siete razones porque la muerte debe ser deseada y no temida»; entre ellas, que es ley universal (V, xii-xiii), que «si la vida es llena de cuidado y cargo, el cabo della no puede ser salvo alivio» (V, xiv), y que «es caduca y flaca nuestra vida, la cual ni puede durar ni preservarse sino cien años», y además «hoy por guerras, discordias, hambres, enfermedades y carestías con gran dificultad acaudalamos la sustentación y necesidad de la vida» (V, xvi). Erasmo, en De praeparatione ad mortem (1534), deja que irrumpa la experiencia cotidiana de la fragilidad de la vida:

dexando aparte los rayos y los terremotos, y las crecidas del mar, las aberturas de la tierra, las guerras y ladronicios, muertes [sic por «homicidia»] y venenos, ¿quién contará todos los linages de las enfermedades? Y en ellos, quántos ay tan espantosos, tan dolorosos, que de solo mentarlos tiembla el hombre. Quales son: la gota coral, la perlesía, el mal de piedra, phrenesía. Dexo de dezir las frequentes pestilencias. (227-28)

11. Ver Huizinga 141-55; Tenenti; Ariès 99-140, 293-316; Vovelle 89-364; para el caso de Espańa, ver Adeva; Gago; Lawrance, 1998. Para otros modelos de muerte y su representación literaria, ver Galván, 2009b.

12. Es traducción del Libro de la preparatione a la morte (h. 1464-1471) de Bartolomeo de' Maraschi (ver Tenenti 83-84); tiene dos ediciones en Sevilla en las primeras décadas del siglo XVI (Gago 33). 
Desde nuestra niñez, ¿qué otra cosa oýmos sino gemidos de los que se mueren? ¿Qué otra cosa vemos sino mortuorios, enterramientos, lloros, sepolturas y letreros de muertos? [...] ¿quién ay que no aya estado dos dedos de la muerte: o por tempestad, o por ladrones, o por guerra, o por desastre, o por pestilencia, o por enfermedad? Dondequiera que te buelvas está la muerte en celada. $(250)^{13}$

Aunque suele decirse que Erasmo renueva en este contexto la visión de la vida y muerte cristianas ${ }^{14}$, no parece cambiar la visión de la vida y muerte humanas. Lo mismo vale para otras artes que seguirían apareciendo durante las muchas décadas en que la tradición mantuvo su vitalidad, con títulos que van desde la Agonía del tránsito de la muerte (1537) de Alejo Venegas hasta De arte bene moriendi (1620) de Roberto Bellarmino. Por este lado, se puede contar con un horizonte bastante estable.

Además de poseer un género específico, la muerte está presente en otros libros de tema más general, alguno de ellos con enorme difusión. Por ejemplo, la biografía sapiencial del emperador filósofo que ofrece Antonio de Guevara en el Libro áureo de Marco Aurelio (1528) -que tuvo unas cincuenta ediciones en el siglo XVI (Whinnom 193)- incluye un relato del imaginario acto fundacional de las artes moriendi. Cuando Marco Aurelio ve acercarse la muerte y se angustia, su secretario Panucio le hace una reprensión; es tan buena que Marco Aurelio se restablece un poco y le ruega que la ponga por escrito. Allí estarán los principales tópicos de las futuras artes de morir: la muerte es ley universal, descanso de las miserias de esta vida y prueba definitiva del esfuerzo del hombre. La realidad cotidiana irrumpe una vez más; en este caso, acerca de la vejez:

después de cinqüenta años que los hombres biven, o se avían de morir o hazer que los matasen, porque hasta allí es la cumbre de la feliçidad humana: todo lo que más bive se le passa al triste viejo en enfermedades graves, en muertes de hijos, en pérdidas de hazienda, en importunidades de yernos, en enterrar amigos, en sustentar pleytos, en pagar deudas y en otros infinitos trabajos, los quales le valiera más a ojos cerrados esperarlos en la sepultura que no teniéndolos abiertos suffrirlos en esta vida. (I, xl: 165-66)

Sin duda Guevara está hablando de algo que los lectores veían a su alrededor. A modo de ejemplo: los reyes de Castilla Enrique IV e Isabel I habían muerto entre los cincuenta y los sesenta años, y lo mismo sucedería al destinatario del Marco Aurelio, Carlos I. (Es en este horizonte donde se convierte en señal muy clara la edad que el Quijote atribuye a su protagonista nada más comenzar; también era significativa la edad del propio Cervantes. Un anciano hablaba de otro anciano) $)^{15}$.

13. Para el texto latino, ver Erasmo, «De praeparatione», 347-48 y 362.

14. Ver Bataillon 558-72; Tenenti 104-09.

15. Hay ya un número significativo de estudios sobre la relación del Quijote con las artes de bien morir (Mazzocchi; Schmidt; Godoy). Aunque la muerte de don Quijote ha sido bastante comentada (ver Fernández), no es frecuente considerarla como un motivo estructurador de toda la novela (pero ver Cull; Lo Ré). 
Lo que era escueta recomendación de las Artes moriendi -meditar sobre la propia muerte, imaginarla y contemplarla-, se encuentra detallado en varios capítulos del Libro de la oración y meditación (1554) de fray Luis de Granada, que parece haber sido el mayor éxito editorial de los siglos XVI y XVII, con un centenar de ediciones (Whinnom 194). Granada amplía varios tópicos que ya han aparecido ${ }^{16}$ y añade otros elementos, entre ellos, la repugnancia de la propia sepultura y cadáver:

Luego naturalmente se representa al hombre en lo que ha de parar su cuerpo [...]. Mira cuán estrecha es aquella casa que se le apareja en la tierra; cuán escura, cuán hedionda, cuán acompañada de gusanos y de huesos y de calaveras de muertos, y cuán horrible, aun de solo mirar, a los vivos. Y como ve que aquel cuerpo a quien él solía tratar con tanto regalo [...] y aquella carne [...] ha de ser echada en tan miserable muladar, y allí ha de ser pisada y comida de gusanos, y allí ha de venir a tener la mesma figura que tiene un rocín que se muere por esos campos, que el caminante se atapa las narices y se da presa a caminar por no olerlo; [...] no puede (si algún juicio tiene) dejar de maravillarse. (I, ii, tratado $3, \S 2: 162-63$ )

En síntesis, el discurso sobre la muerte con autoridad religiosa o sapiencial llama la atención hacia la brevedad y fragilidad de la existencia humana, hacia el ambiente mortuorio que se percibe dondequiera, hacia la multitud de enfermedades y sus dolores, hacia el daño del envejecimiento y la degradación física del cadáver. Es difícil ponderar el sentido de todo esto: en qué medida es una estrategia de temor y terror, como insiste Vovelle (142-46, 296-301, etc.), o si aspira sinceramente a reducir el miedo, a prever las angustias y prevenir sus remedios, a mirar la muerte con serenidad ${ }^{17}$. Pero es verdad que, incluso en esta segunda perspectiva, se paga un alto precio: devaluar la vida, la salud y bienestar corporales, para hacer llevadera su inevitable pérdida.

\section{LA MUERTE EN LOS LIBROS DE CABALLERÍAS}

Sobre el horizonte que se acaba de esbozar, ahora se procederá al análisis del motivo de la muerte en los libros de caballerías. Si los caballeros de ficción son gente despreciadora y vencedora del natural temor a morir, según dice Granada; y si es excepcional que mueran conforme al modelo de las Artes moriendi, según se observa en el Quijote, ¿cómo es exactamente la relación de la muerte y el caballero? ¿Cuál es el papel de la muerte en el dinamismo de su aventura, qué configuraciones espaciotemporales provoca, y qué tipo de experiencia comunicativa sustenta?

La cuestión sería aún más compleja de tomar en consideración la posible prehistoria del Amadis de Gaula, que tan solo se puede mencionar aquí. Como

16. Dedica bastantes páginas a las miserias de la vida, con su brevedad y fragilidad, y a la muerte: lo incierto de su hora, la angustia de la agonía, etc. (parte I, capítulo ii, tratados 2 y 3 ).

17. Ariès encuentra más testimonios de serenidad que de miedo (125-31, 293-310); ver también Tenenti 105; Bataillon 558; Gago 26-31. Una visión bastante ponderada, junto con una conexión con la problemática actual de la muerte, se encuentra en Elias. 
se sabe, la primera edición conservada es de 1508, pero hay bastantes indicios de una versión primitiva que se remonta a la primera mitad del siglo XIV. Esta versión debía de tener un final feliz; más tarde, el Amadis fue ampliado de tal manera que los acontecimientos conducían a una gran batalla aniquiladora (Cacho Blecua 357-400; Avalle-Arce 117-24). Con ello se repetía la evolución histórica que tuvieron los relatos de caballerías franceses, que pasaron de los finales felices de Chrétien de Troyes al exterminio del mundo artúrico en la batalla de Salisbury, exterminio difundido en la llamada "Vulgata» y sus derivados, entre ellos la castellana Demanda del santo Graal (Lida de Malkiel 409). Ahora bien, el Amadis que conservamos, en recensión de Garci Rodríguez de Montalvo, presenta una batalla de aspecto terrible, pero permite a los héroes salir con vida y emprender nuevas aventuras. Este cambio -mídase con respecto a la Demanda o al Amadís previo- es significativo, y además reverbera en toda la estructura del Amadis de Montalvo y sus principales continuadores, como expondré a continuación.

Amadís de Gaula se caracteriza por una extraordinaria capacidad de sufrir muertes aparentes y retornar a la vida. Desde su mismo nacimiento: como es hijo ilegítimo del rey Perión y la princesa Elisena, esta lo abandona en las aguas dentro de una cesta, para que muera y no dé lugar a su deshonra (I, i: 24446); al cabo de algunas aventuras, Perión y Elisena, ya casados, lo reconocen y recuperan ( $\mathrm{I}, \mathrm{x})$. Poco más tarde, Amadís cae en una trampa de Arcaláus el Encantador: "perdió la fuerça de todos los miembros y el sentido, y cayó en tierra tal como muerto», "y todos pensaron que lo matara» (I, xviii: 436-37). Aunque lo restituyen dos doncellas con poderes mágicos ( $\mathrm{I}$, xix), la falsa noticia de su muerte llega a la corte y provoca grandes llantos (I, xx). Más adelante, sufre el despecho de Oriana por un equívoco, de manera que abandona la corte, se aleja del mundo caballeresco y se asocia a un ermitaño, diciéndole: «yo soy llegado a tal punto, que no puedo bevir sino muy poco» (II, xlviii: 705). Efectivamente su situación se agrava, parece llegado al «estrecho de la cruel muerte», pero en ese momento lo reconoce una doncella de Oriana que le da una carta donde se deshace el malentendido, una carta con poder de «te quitar de la muerte» (II, lii: 743-44). Hasta este punto, el itinerario de Amadís está marcado por el acercamiento a una muerte que pueda llamarse propia de su naturaleza y condición. La primera ocasión de muerte es la más impropia, por proceder de su misma madre; continúa con el peligro de la aventura caballeresca, y después llega a casi morir de amor. Pero escapa siempre.

Hay un cambio de signo en la siguiente ocasión mortal, el combate con el monstruo llamado Endriago en la Isla del Diablo. Amadís lucha contra él y lo vence, pero queda tan malherido que, entre desmayos, dice a su escudero: «ya veis que yo soy muerto. Yo te ruego [...] que me seas bueno en la muerte como en la vida lo has sido; y como yo fuere muerto, tomes mi coraçón y lo lleves a mi señora Oriana» (III, lxxiii: 1145). El escudero, con mejor acuerdo, avisa a un médico, el sabio Elisabad, quien consigue curarlo. En este caso, el peligro y la cuasi muerte tienen una coloración religiosa: el monstruo es una figura diabólica, la batalla está preparada y acompañada por plegarias (1140, 
$1147,1150)$, e incluso se fundará un monasterio para conmemorar la victoria de Amadís (III, lxxiv: 1154). Aquí apunta una concepción ideológica de la caballería, según la cual sería más propio del caballero morir por causa de la religión que por aventuras o amores.

Por último, aparece la que posiblemente fue verdadera muerte de Amadís en una versión anterior, pero Rodríguez de Montalvo la ha transformado en varias etapas. Primero se refiere a ella Urganda en términos puramente metafóricos: las hazañas de Amadís serán superadas por las de su hijo Esplandián,

assí que por muchos que más no saben será dicho que el hijo al padre mató. Mas yo digo que no de aquella muerte natural a que todos obligados somos, salvo de aquella que pasando sobre los otros mayores peligros, mayores angustias, gana tanta gloria que la de los passados se olvida. (IV, cxxxiii: 1763)

Sin embargo, el personaje se acerca más a una muerte literal en el siguiente título de la serie, Las sergas de Esplandián, del mismo Montalvo. Padre e hijo traban un durísimo combate (xxviii-xxix); luego, el narrador retoma el argumento que dio Urganda:

algunos dixeron que [...] Amadís de aquellas heridas muriera, y otros que del primer encuentro de la lança, que a las espaldas le pasó. [...] Mas no fue assí, que aquel gran maestro Helisabad le sanó de sus llagas [...]. Pero la muerte que a Amadís le sobrevino no fue otra sino que, quedando en olvido sus grandes fechos casi como so la tierra, florecieron los del fijo con tanta fama, con tanta gloria que a la altura de las nuves parescían tocar. (xxix: 253-54)

Aunque Amadís ha escapado de varios peligros de muerte, parece que no dejará de sucumbir al curso de la naturaleza y de la historia: la siguiente generación va a superarlo. Ya no se trata de morir como es más o menos propio de un caballero, sino como es propio, natural e inevitable a todo viviente. Será, además, la inversión de la primera amenaza de muerte, prematura y antinatural por ocasionarse nada más nacer y a causa de su misma madre. Sin embargo, ni siquiera una muerte tan propia como esta alcanza a Amadís. Al final de Las sergas, Rodríguez de Montalvo introduce un artificio que impide la terminación natural de la vida de los personajes. «Estando Urganda en la su Ínsula No Hallada, supo por sus artes cómo la muerte se allegaba a todos los más principales de aquellos reyes que ella tanto amava» (cxxxiii: 816); entonces, los convoca y les promete: "por muy grandes y largos tiempos fuera de toda la natural orden quedaréis; y no sin esperança de tornar al mundo en aquella perfición de fermosura, en aquella floreciente y fresca edad que la avéis tenido cuando más en vosotros esclareció» (cxxxiii: 818). Y así, los rejuvenece, suspende sus sentidos y los oculta sepultando en el abismo la Ínsula Firme. Queda la expectativa de que retornen al mundo, expectativa que resulta algo irónica al vincularse al retorno del rey Arturo y a la recuperación de Constantinopla (xcix: 547; cxxxiii: 821) ${ }^{18}$.

18. Constantinopla también es un cronotopo que vincula el mundo de la ficción y el de los lectores; ver Galván, 2012. 
Ironía o no, las continuaciones de la obra de Montalvo renuevan estos procedimientos de salvación de la muerte. Alguno de los descendientes de Amadís de Gaula hereda su capacidad de retornar a la vida, incluso de forma más espectacular: a Amadís de Grecia, una doncella «le atravessó con la espada todo el cuerpo, lançándosela toda hasta la cruz; [...] como muerto cayó luego en el suelo tenido», pero una princesa sacó la espada y «el cavallero tornó luego en todo su acuerdo, pareciéndole como que avía estado durmiendo" (Silva, Amadis, I, xxix: 103-04). Mas aun estas cuasi resurrecciones son cosa menor -al cabo, como preguntaba Erasmo, «¿quién ay que no aya estado dos dedos de la muerte [...]?»-; lo peculiar de esta serie caballeresca es la exención del curso natural. Amadís de Gaula, encantado por Montalvo, retorna al mundo de los vivos en la primera continuación escrita por Feliciano de Silva, el Lisuarte de Grecia (xxxii-xxxiii); sigue siendo un gran guerrero, y lleva a cabo maravillas en armas en el cerco de Constantinopla (xlviii). El libro siguiente, Amadís de Grecia, termina como Las sergas, con un encantamiento, precedido de la siguiente advertencia:

Muy soberanos y excelentes príncipes: para que no fuéssedes hechos segundo Lucifer, la magestad divina proveyó de poner en vós y en todos los nacidos la muerte, para que con la memoria díella la vuestra gran sobervia fuesse amansada, la cual (como cosa natural sea a todos bivientes) algunos de los que aquí estáis la tenéis no muy lexos; a cuya causa [...] emos querido que, para remedio al menos díesta que forçadamente á de venir, aquí estéis donde enteramente gozéis todos [...]. Esto no creáis que durará para siempre, porque Dios es sobre todos; mas no saldréis de aquí sino por estrańas aventuras. (II, cxxix: 566)

El discurso es paradójico porque, de un lado, invoca los tópicos de las artes moriendi-es inevitable morir, hay que meditar en ello-, mientras que, de otro, anuncia su anulación mediante la magia. Este funcionamiento se prolonga en la continuación, Florisel de Niquea, y llega a un cambio cualitativo ${ }^{19}$. Hay en este libro nuevos retornos y retiradas a encantamientos preservadores (I, li y lxx; III, lxxxviii), y también remedios ad hoc para el evidente envejecimiento de Amadís (II, xxi-xxiv); pero, al fin, Urganda advierte que el problema es general - «considerando como sois humanos y por tal parte mortales, y que aun antes del tiempo de la muerte el tiempo tiene privilegio contra vuestra hermosura»y ofrece una solución general, para que todos puedan «bivir cien años más de lo que naturalmente avéis de bivir y assí mesmo para que desde aora hasta entonces vuestra fermosura se sostenga en la fuerça de edad de treinta ańos» (III, lxxvi: 233-34). Les da un agua olorosa y una conserva confeccionada con el «fructo del Árbol de Vida que Dios puso en el Paraíso Terrenal», que tienen efecto inmediato (III, xcv: 300) -sin quitar las canas a los caballeros, porque estas ponen «autoridad y magestad a la frescura de sus rostros» (301)-. El memento mori con que iniciaba su razonamiento queda otra vez vacío; más aún, el poder de Urganda se extiende a derogar el de Dios, que fue quien alejó al hombre del

19. No he tenido acceso a los libros I y II de Florisel; remito a la sinopsis de Montero García $(27,33,41-42)$. 
árbol de la vida (Génesis 3, 22). Desde este punto, Feliciano de Silva no necesita retirar a los personajes mediante encantamientos que los libren de la vejez y de la muerte. Todos pueden disfrutar de la vida en la corte y emprender nuevas aventuras en el cuarto y último libro de Florisel.

Como se puede ver, la serie de los Amadises entra en una relación irónica y productiva con el discurso normativo sobre la muerte. La amenaza de la muerte, inherente a la aventura, se hace acuciante por acoger los tópicos de las artes moriendi; y por eso mismo es más maravilloso que los personajes escapen a su destino mortal. Lo propio del caballero resulta ser el permanecer cerca de la muerte pero diferirla continuamente. Escapa al curso natural de inevitable decadencia y extinción para entrar en una suerte de ritmo sistólico-diastólico: alterna el retirarse a lugares encantados con el volver al mundo habitual para participar en batallas y otros acontecimientos importantes. El último retorno al mundo no conduce a la muerte, sino a otro tipo de encantamiento preservador. Lo que esto genera es una diferencia cualitativa respecto del mundo real, en un cronotopo imposible. Este cronotopo responde ciertamente a la matriz folklórica descrita por Bakhtin: el valor se manifiesta como extensión. Ahora bien, mientras que Bakhtin diferencia entre el cronotopo folklórico de la vida comunitaria y el cronotopo histórico del individuo, aquí se produce una fusión de tipo maravilloso: la vida individual se hace infinita, y las generaciones no se suceden, se acumulan en una sola comunidad de espléndida juventud.

Desde este punto se advierte mejor qué es lo específico de Tirante el Blanco. No difiere del Amadis en la capacidad del caballero para casi morir y volver a la vida. A Tirante lo dan por muerto en varias ocasiones: ya después de un combate en que pierde mucha sangre (I, lxvii: 133-34), ya después de una peripecia amorosa, cuando él mismo se finge alma en pena para escapar de los vigilantes (III, ccxxxiv: 632-34). Un desengaño amoroso le causa tal dolor que se prepara realmente para morir, orando y confesándose (III, ccxci: 736). Especialmente, durante una tempestad teme por su vida y dispone por escrito su sepultura; pero escapa, queda desnudo en tierra de moros y disimula su identidad, en lo que constituye una especie de nuevo nacimiento, comienzo de una nueva etapa en su vida aventurera (III, ccxcix-IV, ccci: 754-55, 758, 766). Cuando le recuerdan el amor de la princesa de Constantinopla, cae sin sentido y todos creyeron "que oviesse dado el spíritu a Dios y el cuerpo a la tierra» (IV, ccclvii: 891); pero se recupera y vuelve a Constantinopla. Así pues, Tirante es igual que Amadís en su capacidad para escapar de peligros de muerte y revivir.

La diferencia es que Tirante no se libra del curso natural; sucumbe a la enfermedad, ya que no a la vejez. Al poco de triunfar definitivamente sobre los sarracenos, lo toma un mal de costado (V, cdlxvii: 1064). Reza, testa, muere y es sepultado; la Princesa y el Emperador lo siguen de inmediato. Ahora bien, si la forma de morir es la prescrita en las Artes, la lección se aplica principalmente a otro aspecto: "Enxemplo manifiesto a los venideros que no se confíen de la fortuna» (1063). Para el narrador, lo significativo es el hecho de que su personaje muere poco después de su mayor éxito, y de forma repentina; no el que muera como todos hemos de morir ni la manera en que administra su muerte. Esta 
muerte puede resultar impropia desde el punto de vista interno, la trama de la obra, pero es propia desde el punto de vista externo, el cronotopo del autor y sus lectores. La Fortuna es un tópico dominante en el siglo XV, y un dolor de costado fue quizá lo que mató, por ejemplo, a Juan de Mena y a Enrique IV por los mismos ańos que a Tirante. Por otro lado, la muerte del caballero no es el punto final de esta novela; la vida sigue en Constantinopla, la Emperatriz viuda se casa con su joven amante Hipólito, a quien «la fortuna le prosperó y favoreció tanto que, por su mucha virtud y alta cavallería aumentó y acrecentó mucho su Imperio [...], bivió mucho tiempo», tuvo hijos y repartió una gran herencia (V, cdlxxxvii: 1101). Se combinan, por tanto, un compromiso ideológico en el tratamiento de la vida individual cerrada y una matriz folklórica en la superación de ese momento. La yuxtaposición de los dos aspectos produce una fuerte ambigüedad (ver Lawrance, 1999), que naturalmente es más nociva para la ideología que para el folklore.

Es posible, sin embargo, un contraste entre lo normativo y lo folklórico contenido en los cauces de la ideología, como se produce en una continuación de Amadís de Gaula, menos fantástica y más moralizante que las de Feliciano de Silva: Lisuarte de Grecia y muerte de Amadis de Juan Díaz (ver Sales Dasí, 12532). Este libro presenta el itinerario caballeresco convencional de Lisuarte, hijo de Esplandián y nieto de Amadís: endereza tuertos, lucha contra la magia, libera caballeros, y naturalmente se enamora de una princesa, Elena de Macedonia (xlix-li), y termina casándose con ella (clxxv-clxxxiii). En contrapunto con estas aventuras se narra el ocaso de Amadís de Gaula. En la primera mitad del libro, Amadís está en la cumbre de su poder, y es capaz de dirigir la guerra contra los infieles y combatir él mismo (cii-cx), pero poco después Urganda profetiza su muerte (cxvi). En efecto, algunas derrotas lo hunden en la tristeza y la enfermedad (cxl, cl, clv); se siente «viejo cansado» (clix: 189v), entra en fase terminal (clxi), dirige a todos sus parientes un largo discurso que hace en parte de consolación y en parte de testamento (clxiii), recibe los sacramentos, pronuncia una oración y «dio el ánima a su creador, en braços de aquella noble reyna Oriana» (clxiv: 194v-195r). Siguen el duelo, el sepulcro, las exequias (clxv-clxvi), y sus restos se trasladan a un monasterio fundado por él (clxxxiv). Es una muerte inequívocamente natural en su proceso y ejemplar en sus $\operatorname{actos}^{20}$. Sin embargo, no es esta la última palabra; el capítulo final se dedica a la grandeza del reinado de Lisuarte y a las hazañas de sus hijos, bisnietos de Amadís (clxxxvii). Se trata de una conclusión ascendente que, por basarse en el linaje legítimo del caballero, no tiene el efecto deletéreo de la del Tirante. Ahora bien, hecha abstracción de la diferencia en ambigüedad e ironía, Tirante y Lisuarte son los libros que más se ajustan al modelo folklórico expuesto por Bakhtin. La paradoja es que este modelo puede ser el que mejor se adapta al uso ideológico, pues combina la muerte ejemplar de un individuo con la prolongación de su grupo, su modo de vida, su carisma y su poder.

20. También el Tristán castellano adaptó la muerte del caballero a la normativa social y eclesiástica; ver Cuesta Torre, 2008. 
El último modelo de muerte caballeresca que voy a examinar se encuentra en la serie de los Palmerines. Esta comienza con dos libros anónimos de la segunda década del XVI, Palmerín de Olivia y Primaleón. El fundador del linaje alcanza el trono de Constantinopla al final del primer libro, y al final del segundo tiene una muerte accidental pero serena y bien ordenada; sin embargo, el relato es demasiado sumario para considerarlo ejemplar: "fizo todo aquello que le convenía para su alma y castigó a Primaleón que siempre se uviesse sesudamente en su regimiento" (ccxvii: 537). La continuación más famosa, el Palmerín de Inglaterra -aprobada y absuelta en el escrutinio de la biblioteca de don Quijote-, se desentiende de esta muerte de Palmerín de Olivia y lo presenta en el trono de Constantinopla. No se trata, sin embargo, de un retorno mágico a la plenitud vital como el que se encuentra en los Amadises. En Palmerín de Inglaterra, la primera generación caballeresca ofrece un contrapunto de envejecimiento y extinción a las aventuras amorosas y bélicas de los jóvenes. Primero muere el emperador Trineo de Alemania, cuñado de Palmerín de Oliva (I, xcv); después, el rey Fadrique de Inglaterra, su consuegro (II, xxxv). Sobre todo, el propio emperador Palmerín va decayendo. Está «flaco y viejo» (I, lxxxii: 307), ya no puede justar (II, x), espera la muerte (II, xi y xlviii), llora con facilidad, «que este es el naural de los viejos» (II, xxxiii: 211). La muerte de Fadrique lo afecta especialmente,

que como fuesen de una edad, parecíale que éstas fuesen espías de su fin, como sea natural la mayor enfermedad que la vejez trae consigo, traer siempre delante los ojos la muerte. Y este pensamiento o representación de la memoria la corrompe el juicio, trastorna el entendimiento [...]. Que así aconteció al emperador con esta nueva: [...] que las palabras que decía eran dichas sin concierto. (II, xxxv: 224).

Aquí se airea una posición más crítica frente a un tópico de las artes de morir: que conviene meditar en la propia muerte. En conjunto, el libro se hace con una voz independiente respecto de dichas artes, y da una visión singular de la muerte, presentándola como proceso biológico, que va a llevar hasta el fin y a convertir en compendio de todo un mundo histórico. Efectivamente, el siguiente paso es que Palmerín se queda inválido (II, liii), y entonces Constantinopla recibe el ataque de un enorme ejército. En la primera batalla campal, los defensores sufren grandes daños, y en la ciudad hubo tal llanto y muestra de sentimiento, "que hizo tanta impresión en el emperador Palmerín, que hizo su postrero fin» (II, lxiv: 384). Este acontecimiento da el tono para el último acto de la novela: el ejército se cubre de luto para la siguiente batalla, luego quema su propia ciudad para luchar más desesperadamente, y logra la victoria pero con grandísimas pérdidas. «Esta se puede creer que fue la más notable batalla del mundo, por las muchas muertes que en ella hubo y el deseo de morir que quedó en los que quedaron» (II, lxv: 403). El rey Duardos y el nuevo emperador Primaleón, herederos de Fadrique y Palmerín, resultan malheridos y se desconfía de su curación; se los lleva el sabio Daliarte, mientras el pueblo «lloraba su desventura, sintiendo por grave cosa hasta los huesos de sus príncipes no dejárselos poseer» (II, lxvi: 404). En resumen, la muerte de Palmerín 
de Oliva se presenta como un hecho biológico, una consunción progresiva de su cuerpo y sus facultades mentales. El dinamismo narrativo y la orientación hacia el final del libro no vienen, como en otros casos, por repetición de peligros y apariencias de muertes, sino por las repetidas referencias a la marcha de ese proceso natural. Además, la decadencia de Palmerín sirve primero de contrapunto a las aventuras caballerescas, y después se va sincronizando con el proceso histórico que provoca el ocaso de Constantinopla. Así, en este libro hay dos muertes propias, la natural del anciano y la gloriosa del caballero, más la propiedad que resulta de su armonía. Desde el punto de vista del cronotopo, se renuncia a prolongar la vida de la comunidad más allá de la muerte del individuo que la encabeza. Si la distinción de esas dos líneas durante buena parte del libro manifiesta la divergencia entre el tiempo individual y el tiempo colectivo, descrita por Bakhtin (214-17), su reunión final, recortando la historia de la comunidad a la medida de lo que dura una vida individual, produce una suerte de humanización del tiempo histórico.

\section{Conclusiones}

El primer rendimiento del poner los libros de caballerías en el horizonte del discurso sobre la muerte es que se advierte mejor su diversidad estructural ${ }^{21}$. Los peligros mortales y las muertes aparentes son elementos convencionales, bastante uniformes, como los gigantes, los encantamientos y las doncellas en apuros, pero también constituyen una recurrencia que origina diversas formas narrativas. Desde este punto de vista, se encuentran materiales para ir sistematizando el papel que el concepto de muerte puede tener en la teoría literaria: en el dinamismo narrativo, en el cronotopo y en la comunicación literaria, como expondré a continuación.

En primer lugar, como ya se ha dicho, el juego de repetición y diferencia origina un ritmo y un sentido de progresión hacia determinado final. Precisamente, en el final se dan las divergencias más significativas. Estos libros terminan con una transformación cualitativa: tras las variaciones sobre el tema de la muerte violenta, pasan a la muerte por causa natural, sea enfermedad o, más habitualmente, envejecimiento; $y$, o bien el caballero escapará a esta muerte natural, como a las anteriores, o bien sucumbirá a ella. Entonces se produce una tensión entre lo igual y lo diferente, lo propio y lo impropio. En la serie principal de Amadís, lo propio del caballero es no morir, primero porque escapa de los peligros accidentales, pero finalmente porque se le preserva de la muerte natural. Así, todas las ocasiones de muerte son iguales, en el sentido de igualmente evitables, y el caballero, a fuerza de ser idéntico a sí mismo, termina por ser diferente de la humanidad. En el extremo opuesto, Tirante sucumbe a una muerte que no le es propia, no es caballeresca: difiere de sí mismo al morir, pero con ello se iguala al común de los mortales y por eso mismo puede servir

21. Sobre esta diversidad estructural, ver también Galván, 2009a. 
de ejemplo (como el Amadís marginal de Juan Díaz). El Palmerín de Inglaterra utiliza una técnica diferente: no son los peligros mortales de los caballeros, sino el envejecimiento del Emperador y su aproximación a la muerte lo que funciona como el tic-tac de un reloj que marca el ritmo narrativo, cuyo último compás desencadena la destrucción de Constantinopla, con la saturación de propiedad que ya se ha comentado.

En segundo lugar, el cronotopo se ve afectado por las diferencias de trama ocasionadas por la muerte. El cronotopo folklórico descrito por Bakhtin se reconoce en Tirante el Blanco y Lisuarte y muerte de Amadis: el individuo muere, pero su linaje y su sociedad siguen viviendo. Hay que señalar la variedad que cabe dentro de un mismo tipo, desde la ambigüedad burlona del Tirante hasta la moralización de Lisuarte; por eso mismo, también hay que señalar que el cronotopo folklórico se presta a usos ideológicos, por más que Bakhtin contrapone los dos conceptos. En cualquier caso, estos dos libros son atípicos entre los de caballerías: se conoce la poca fortuna editorial de Tirante (Whinnom 189; Eisenberg 136), y Lisuarte quedó al margen de las principales continuaciones del Amadis. Lo que predomina en el género es que, contando a priori con la distinción entre lo individual y lo colectivo, se elabora su unificación, y esto de dos maneras. La serie principal de los Amadises, de Rodríguez de Montalvo y Feliciano de Silva, se caracteriza por la liberación, siempre provisional pero siempre prorrogada, de la necesidad de morir, de tal manera que las generaciones precedentes se van sumando a las nuevas. La vida individual toma la forma de la vida colectiva, y el tono dominante es siempre el de la generación joven; la prolongación temporal se completa con la extensión espacial, en continuas andanzas aventureras. Si el cronotopo folklórico y renacentista, como dice Bakhtin, identifica extensión y valor, está claro que los autores de los Amadises se resisten a restar valor a la vida individual, y a remitir a su perduración genérica en nuevas generaciones formadas por otros individuos. El movimiento inverso se da en Palmerín de Inglaterra, al ajustar la historia de la colectividad a los límites de una vida individual sujeta a la decadencia biológica; desemboca en una estasis espacial, con los caballeros copados en el cerco de Constantinopla, y con una aniquilación que parece el final apocalíptico de los tiempos. Lo forzado de los procedimientos narrativos que se emplean en uno y otro caso pone de manifiesto que se trata de restaurar una unidad de lo personal y lo comunitario que la conciencia general ya había perdido.

En los libros de caballerías está en marcha la decantación de una poética de la narración y la muerte que se percibe más claramente a posteriori, desde la atalaya del Quijote. Esta novela cuenta cómo llega a morir alguien que está muerto desde la primera frase: «no ha mucho que vivía». Don Quijote sabe que pueden matarlo en cualquier momento «unas calenturas pestilentes» (I, xix: 188), y tiene hecho su testamento (I, xx); la primera parte tan solo le da para una muerte aparente (I, lii), aunque seguida de un soneto de epitafio para su sepultura. La segunda parte anuncia desde el prólogo un don Quijote «muerto y sepultado» (561). El personaje anuncia: "caballero andante he de 
morir» (II, i: 566), pero como tal solo alcanza una muerte simbólica: «aprieta, caballero, la lanza, y quítame la vida, pues me has quitado la honra» (II, lxiv: 1041). La muerte real será del individuo Alonso Quijano, aunque la vida sigue: "comía la sobrina, brindaba el ama, y se regocijaba Sancho Panza; que esto del heredar algo borra o templa en el heredero la memoria de la pena que es razón que deje el muerto» (II, lxxiv: 1097), un atisbo de la continuidad social que desarrollaban algunos libros de caballerías. Pero en el Quijote importa más la fusión de vida y narrativa, de muerte del personaje y clausura del texto.

Por último, hay que considerar el aspecto comunicativo. Estos libros interpelaban a lectores con una determinada experiencia del curso natural y un discurso autorizado sobre la muerte. Michel Vovelle ha escrito que la literatura y la filosofía del siglo XX se ocupan mucho de la muerte para compensar el tabú que la sociedad ha impuesto sobre ella (739). Aquí se ha examinado la situación contraria: en el siglo XVI había una hipertrofia de discursos sobre la muerte en respuesta a las penalidades de la corta esperanza de vida, la enfermedad y el envejecimiento que hoy consideraríamos prematuro. Pero la estrategia del discurso normativo, devaluar la vida para disminuir el miedo a la muerte, generaba un nuevo déficit. La compensación para este último la elaboran los libros de caballerías, devaluando la muerte para que resplandeciesen las vidas espectaculares de sus héroes. Esta compensación existencial está en la base de otras, de tipo ideológico, que pudieron brindar aquellos libros: de la abstracción y deshumanización del tiempo histórico, como sugiere el análisis del cronotopo; de la autonomía aristocrática perdida en el Estado moderno, según explican Maravall (30-31, 114-15) y Chevalier (96-103). El atender al papel de la muerte permite hacerse cargo del arraigo de la comunicación literaria en las condiciones de la existencia biológica y social. En el caso de los libros de caballerías, lo que encontramos parece ser una actitud evasiva pueril; pero es una puerilidad que no puede mirarse como cosa ajena, si tiene razón Norbert Elias cuando señala «una fuerte tendencia en las sociedades desarrolladas de nuestros días» a «evitar el pensamiento de la muerte», bien «alejando de nosotros cuanto sea posible su indeseable presencia», bien «mediante la firme creencia en la inmortalidad personal: "otros mueren, pero yo no"» (7). Esto último podría haberlo dicho Amadís de Gaula. En conclusión, los libros de caballerías ponen ante nuestros ojos, distanciada y objetivada, la doxa actual, que debe someterse al escrutinio de la Teoría ${ }^{22}$.

22. Una versión previa de este trabajo se presentó en el II. ${ }^{\circ}$ congreso de la serie «Literatura y Sociedad» organizada por la Universidad de Navarra-GRISO, la Universidad Hebrea de Jerusalén y la Universidad Cheikh Anta Diop de Dakar. Agradezco a los organizadores del II. ${ }^{\circ}$ congreso, especialmente a Ignacio Arellano y Carlos Mata, la oportunidad de presentar esta propuesta; y a los participantes en el coloquio -especialmente a Ruth Fine, Jesús G. Maestro y Javier de Navascués-, sus observaciones y sugerencias. 


\section{Obras citadas}

Adeva Martín Ildefonso, «Los Artes de bien morir en España antes del maestro Venegas», Scripta Theologica, 1984, 16, p. 405-15.

Alcalá Jaime de, Caballería Cristiana, Alcalá, Juan de Villanueva, 1570, 286 p.

Arendt Hannah, «Karl Marx and the Tradition of Western Political Thought», Social Reseach, 2002, 69 no 2, p. 273-319.

Ariès Philippe, L'Homme devant la mort, Paris, Seuil, 1977, 641 p.

Arte de bien morir y Breve confesionario [1479-1484], ed. Francisco Gago Jover, Palma de Mallorca, J. J. de Olañeta, 1999, 172 p. (Arte-a).

Arte de bien morir y Breve confesionario, Zaragoza, Pablo Hurus, c. 1488-1491, 95 p. (Arte-b).

Avalle-Arce Juan Bautista, Amadís de Gaula: el primitivo y el de Montalvo, México, FCE, 1990, $463 \mathrm{p}$.

Bakhtin Mikhail M., The Dialogic Imagination: Four Essays, trad. C. Emerson y M. Holquist, Austin, University of Texas Press, 1981, 444 p.

Bataillon Marcel, Erasmo y España: estudios sobre la historia espiritual del siglo XVI, México, FCE, 1966, 921 p.

Benjamin Walter, «Der Erzähler» [1936], en Gesammelte Schriften, II.2: Aufsätze, Essays, Vorträge, Frankfurt a.M., Suhrkamp, 1991, p. 438-65.

Brooks Peter, Reading for the Plot: Design and Intention in Narrative, Cambridge (Mass.), Harvard UP, 1984, 363 p.

- Psychoanalysis and Storytelling, Oxford, Blackwell, 1993, 144 p.

Cacho Blecua Juan Manuel, Amadis de Gaula: heroísmo mitico cortesano, Madrid, Cupsa, 1979, 439 p.

Casta Isabelle, Nouvelles mythologies de la mort, Paris, Champion, 2007, 228 p.

Cervantes Miguel de, El ingenioso hidalgo don Quijote de la Mancha, ed. Martín de Riquer, Barcelona, Planeta, 2004, 1138 p.

Chevalier Maxime, Lectura y lectores en la España de los siglos XVI y XVII, Madrid, Turner, 1976, $199 \mathrm{p}$.

Cuesta Torre M. ${ }^{a}$ Luzdivina, «La realidad histórica en la ficción de los libros de caballerías», en Eva Belén Carro Carbajal, Laura Puerto Moro y María Sánchez Pérez (eds.), Libros de caballerías (de "Amadis» al "Quijote»): poética, lectura, representación e identidad, Salamanca, SEMYR, 2002, p. 87-109.

— «E así murieron los dos amados’: un episodio del Tristán castellano de 1501 a la luz de sus correlatos castellanos, franceses e italianos». Comunicación presentada al II Congreso Internacional de la SEMYR. San Millán de la Cogolla, 10-13 de septiembre de 2008.

Cull John T., "Death as the Great Equalizer in Emblems in Don Quixote», Hispania, 1992, 75, p. 10-19.

Derrida Jacques, La Carte postale: de Socrate à Freud et au-delà, Paris, Flammarion, 1980, $551 \mathrm{p}$.

Díaz Juan, El octavo libro de Amadís, que trata de las estrañas aventuras y grandes proezas de su nieto Lisuarte, y de la muerte del inclito rey Amadis, Sevilla, J. y J. Cromberger, 1526, 223 fol. 
Eagleton Terry, Después de la Teoría, Barcelona, Debate, 2005, 234 p.

Eisenberg Daniel, Romances of Chivalry in the Spanish Golden Age, Newark, Juan de la Cuesta, 1982, 182 p.

Elias Norbert, La soledad de los moribundos, México, FCE, 1987, 111 p.

Erasmo de Rotterdam, «De praeparatione ad mortem», en Opera omnia, V.1, ed. A. van Heck, Amsterdam-Oxford, North Holland Publishing Co., 1977, p. 321-92.

- Preparación y aparejo para bien morir, trad. Bernardo Pérez de Chinchón, ed. Joaquín Parellada, Madrid, Fundación Universitaria Española - Universidad Pontificia de Salamanca, 2000, 354 p.

Fernández Jaime, «Visión de la crítica en el siglo XX sobre la muerte de don Quijote», Edad de Oro, 2006, 25, p. 141-55.

Gago Jover Francisco, «Presentación», en Francisco Gago Jover (ed.), Arte de bien morir y Breve confesionario, Palma de Mallorca, J. J. de Olañeta, 1999, p. 19-52.

Galván Luis, "Mito, interés y compromiso: arquetipos narrativos de los libros de caballerías», Rilce, 2009a, 25 no 1, p. 102-21.

— "Cuándo será que pueda': ocio, contemplación, muerte y Poética», en Martin Baxmeyer, Michaela Peters, Ursel Schaub (eds.), El sabio y el ocio: Zur Gelehrsamkeit und Musse in der spanischen Literatur und Kultur des Siglo de Oro, Tübingen, Narr, 2009b, p. 55-69.

— «Educación, propaganda, resistencia: Literatura y Poder en teorías, tópicos y controversias de los siglos XVI y XVII», en I. Arellano, Ch. Strosetzki y E. Williamson (eds.), Autoridad y poder, Madrid, Iberoamericana, 2009c, p. 51-87.

— «La península imaginaria: los libros de caballerías y las relaciones entre Castilla y Portugal”, Colóquio Letras, suplemento al no 178, Siglo de Oro: Relaçôes hispanoportuguesas no século XVII, setiembre 2011, p. 48-57

Garreau Bernard-Marie (dir.), Les Représentations de la mort: actes du colloque organisépar le CRELLIC (Centre de recherche en littératures, linguistique et civilisations); Université de Bretagne-Sud, Lorient, 8-10 novembre 2000, Rennes, Presses universitaires de Rennes, 2002, 344 p.

Glaser Edward, «Nuevos datos sobre la crítica de los libros de caballerías en los siglos XVI y XVII», Anuario de Estudios Medievales, 1966, 3, p. 393-410.

Godoy Gallardo Eduardo, «El arte de bien morir en el Quijote», en Ignacio Arellano y Eduardo Godoy (eds.), Temas del barroco hispánico, Madrid-Frankfurt, Universidad de Navarra-Iberoamericana-Vervuert, 2004, p. 129-47.

Granada Luis de, Obras completas. 1, Libro de la oración y meditación, ed. Álvaro Huerga, Madrid, Fundación Universitaria Española-Dominicos de Andalucía, 1994, $644 \mathrm{p}$.

- Obras completas. 10, Introducción del símbolo de la fe (II), ed. Jesús García Trapiello y Álvaro Huerga, Madrid, Fundación Universitaria Española-Dominicos de Andalucía, 1996, 365 p.

Guevara Antonio de, Libro áureo de Marco Aurelio, en Obras completas, ed. Emilio Blanco, Madrid, Turner, 1994, vol. 1, p. 1-333.

Huizinga Jan, Le Déclin du Moyen Age, Paris, Payot, 1967, 345 p.

Jacquin G. (dir.), Le Récit de la mort: écriture et histoire, Rennes, Presses universitaires de Rennes, 2003, 170 p. 
Lawrance Jeremy N. H., "Death in Tirant lo Blanc», en Arthur Terry (ed.), Tirant lo Blanc: New Approaches, Londres, Tamesis, 1999, p. 91-107.

- «La muerte y el morir en las letras ibéricas al fin de la Edad Media», en Aengus Ward (coord.), Actas del XII Congreso de la Asociación Internacional de Hispanistas, Birmingham, University of Birmingham, Department of Hispanic Studies, 1998, vol. 1, p. 1-26.

Lida de Malkiel María Rosa, "Arthurian Literature in Spain and Portugal», en Roger Sherman Loomis (ed.), Arthurian Literature in the Middle Ages: A Collaborative History, Oxford, Clarendon Press, 1979, p. 406-18.

Lo Ré A. G., "The Three Deaths of Don Quixote: Comments in Favor of the Romantic Critical Approach», Cervantes: Bulletin of the Cervantes Society of America, 1989, 9, p. $21-41$.

López Pinciano Alonso, Philosophia antigua poética, vol. 1, Madrid, Marsiega, 1953, $305 \mathrm{p}$.

Lucía Megías José Manuel, «Una nueva página en la recepción de los libros de caballerías: las anotaciones marginales», en Eva Belén Carro Carbajal, Laura Puerto Moro y María Sánchez Pérez (eds.), Libros de caballerías (de "Amadís» al "Quijote»): poética, lectura, representación e identidad, Salamanca, SEMYR, 2002, p. 201-44.

Maravall José Antonio, Utopía y contrautopia en el "Quijote», Madrid, Visor, 2006, $252 \mathrm{p}$.

Martorell Joanot, Tirante el Blanco, ed. Martín de Riquer, Barcelona, Planeta, 2006, $1126 \mathrm{p}$.

Mazzocchi Giuseppe, "La morte di don Chisciotte e le Artes Bene moriendi», Confronto Letterario, 1995, 12 no 24, p. 581-97.

Menéndez Pelayo Marcelino, Orígenes de la novela [1905-1910], vol. 1, Madrid, CSIC - Santander, Aldus, 1943, 466 p.

Montero García Gema, Florisel de Niquea, partes I-II (Valladolid, Nicolás Tierri, 1532): guía de lectura, Alcalá de Henares, Centro de Estudios Cervantinos, 2003, 106 p.

[Moraes, Francisco de], Palmerín de Inglaterra. 2 vols., Madrid, Miraguano, 1982, $408+410$ p.

Palmerín de Olivia, ed. Giuseppe di Stefano, Alcalá de Henares, Centro de Estudios Cervantinos, 2004, 419 p.

Picard Michel, La Littérature et la mort, Paris, PUF, 1995, 193 p.

Primaleón, ed. M. a Carmen Marín Pina, Alcalá de Henares, Centro de Estudios Cervantinos, 1998, 555 p.

Rodríguez de Montalvo Garci, Amadis de Gaula, ed. Juan Manuel Cacho Blecua, 2 vols., 4. ${ }^{\text {a }}$ ed., Madrid, Cátedra, 2001, 1807 p.

- Las sergas de Esplandián, ed. Carlos Sainz de la Maza, Madrid, Castalia, 2003, 877 p.

Rodríguez Velasco Jesús, «Teoría de la fábula caballeresca», en Eva Belén Carro Carbajal, Laura Puerto Moro y María Sánchez Pérez (eds.), Libros de caballerías (de "Amadís" al "Quijote»): poética, lectura, representación e identidad, Salamanca, SEMYR, 2002, p. 343-58.

Sales Dasí Emilio José, «Las continuaciones heterodoxas (el Florisando [1510] de Páez de Ribera y el Lisuarte de Grecia [1526] de Juan Díaz) y ortodoxas (el Lisuarte de 
Grecia [1514] y el Amadis de Grecia [1530] de Feliciano de Silva) del Amadís de Gaula», Edad de Oro, 2002, 21, p. 117-52.

Santaella Rodrigo de, Arte de bien morir, muy copiosa y devota para todo fiel cristiano, S.l., s.f., 42 p.

Schmidt Rachel, "The Performance and Hermeneutics of Death in the Last Chapter of Don Quijote», Cervantes: Bulletin of the Cervantes Society of America, 2000, 20, p. 101-26.

Silva Feliciano de, Lisuarte de Grecia, ed. Emilio J. Sales Dasí, Alcalá de Henares, Centro de Estudios Cervantinos, 2002, 229 p.

- Amadis de Grecia, ed. Ana Carmen Bueno Serrano y Carmen Laspuertas Sarvisé, Alcalá de Henares, Centro de Estudios Cervantinos, 2004, 581 p.

- Florisel de Niquea (tercera parte), ed. Javier Martín Lalanda, Alcalá de Henares, Centro de Estudios Cervantinos, 1999, 500 p.

Tenenti Alberto, Il senso della morte e l'amore della vita nel Rinascimento [1957], Torino, Einaudi, 1989, 511 p.

Thomas Henry, Las novelas de caballerias españolas y portuguesas, Madrid, CSIC, 1952, $261 \mathrm{p}$.

Vovelle Michel, La Mort et l'Occident: de 1300 à nos jours, Paris, Gallimard, 1983, $793 \mathrm{p}$.

Whinnom Keith, "The problem of the Best-seller in Spanish Golden Age Literature», Bulletin of Hispanic Studies, 1980, 57, p. 189-98.

Zanatta Marcello (ed.), Homo moriens: ermeneutiche della morte da Omero a oggi, Cosenza, L. Pellegrini, 2006, 480 p. 